(2014). Mobile Adaptive Communication Support for Vocabulary Acquisition. Journal of Learning Analytics, 1 (3), 173-175.

\title{
Mobile Adaptive Communication Support for Vocabulary Acquisition
}

\author{
Carrie Demmans Epp \\ TAGlab, Dept. of Computer Science, University of Toronto, Canada \\ carrie@taglab.ca
}

\begin{abstract}
This work explores the use of an adaptive mobile tool for language learning. A schoolbased deployment study showed that the tool supported learning. A second study is being conducted in informal learning environments. Current work focuses on building models that increase our understanding of the relationship between application usage and learning.
\end{abstract}

KEYWORDS: Mobile assisted language learning, MALL, English language learning, modelling

\section{INTRODUCTION}

Learning a language is a difficult but rewarding experience. English is one example of a language where achieving mastery has economic benefits (Saiz \& Zoido, 2005). This leaves many North Americans still in the process of learning English at an economic disadvantage (Gambino, Acosta, \& Grieco, 2014). The use of mobile tools has been proposed to help alleviate this problem, but the use of mobile assisted language learning (MALL) has yet to be fully tested or adopted (Burston, 2014).

To better understand and support English language learner (ELL) needs, user-centred design was employed to develop an adaptive language learning and communication support tool. This MALL tool is called VocabNomad and it runs on android smartphones. It is intended to support learning by exposing ELLs to contextualized language usage. VocabNomad was developed and validated through a series of deployment and laboratory based studies (Demmans Epp, 2013). Following these formative evaluations, VocabNomad's effect on learning and the learning environment were assessed using a term-long deployment of the system in a Japanese high school. A second deployment study was then conducted where ELLs used the application during their everyday lives in a major Canadian city. These studies combined the use of detailed application logging with standardized and adaptive tests. This is allowing for the development of models that describe how specific mobile learning activities contribute to ELL vocabulary learning.

\section{BACKGROUND}

Spaced repetition has received considerable attention, with learning analytics leading to improved spacing algorithms (Godwin-Jones, 2010). However, many approaches to language learning have not received the same level of attention (Ballance, 2013; Burston, 2014) even though previous research suggests their importance (Graves, 2013; Wagner, Muse, \& Tannenbaum, 2007). Among these 
(2014). Mobile Adaptive Communication Support for Vocabulary Acquisition. Journal of Learning Analytics, 1 (3), 173-175.

approaches is situated learning or the use of language in context (Carey, 2004; Swain, 1995).

The majority of previous evaluations of MALL tools that rely on the learner's context to support learning have been relatively short (Burston, 2014) with gains for specific vocabulary being observed. However, few studies have measured changes in global vocabulary knowledge (Burston, 2014) and even fewer have linked specific learner activities within MALL tools to gains in vocabulary knowledge (Ma, 2013). This means that we do not understand how learners benefit from different activities within MALL tools.

\section{METHODOLOGY}

To begin addressing the limited evaluation of MALL technologies and our lack of understanding of how MALL tool usage affects language learning, two evaluations of VocabNomad were planned. The first classroom-based study, now completed, used a non-equivalent control group design. Data collection has also been completed for the second study. This study takes place in informal learning environments and uses a single-subject with reversal design.

Both studies use a set of language assessments that measure global vocabulary knowledge (i.e., PPVT-4) and morphological knowledge (i.e., one's knowledge of how words are formed). The second study also tests participant vocabulary learning using an adaptive test based on participant exposure to learning materials within VocabNomad. In addition, VocabNomad performs detailed logging of student actions at the level of individual screen touches within the application: every character entered, scroll, and interface element touched is logged along with the timestamp of when the action took place. Unsupervised classification techniques (e.g., k-means clustering) are applied to these logs, and the resulting models will be used as an input to another model that describes the relationship between system usage patterns, the learner's morphological knowledge, and changes in his/her vocabulary knowledge. The combination of these data will help us to create models that enable our understanding of how system usage affects vocabulary learning rather than how the amount of system usage affects ELL vocabulary knowledge.

\section{RESULTS}

As expected, the first study showed gains in student global vocabulary knowledge when participants were using the application. It also showed that students' believed that their English-language abilities had improved. I am currently trying to build a model that relates student actions within the system to their learning gains using a discovery with models approach.

\section{CONCLUSION}

Data collection for the study of VocabNomad in informal learning environments was recently completed. The data from this study will be used to validate any of the models that can be identified using the data from the classroom-based study. This will allow us to see how well models of MALL usage 
(2014). Mobile Adaptive Communication Support for Vocabulary Acquisition. Journal of Learning Analytics, 1 (3), $173-175$.

generalize across learning contexts. It may also help us to better understand how to use these tools effectively by highlighting which learner actions within MALL systems are linked with positive learning outcomes.

\section{ACKNOWLEDGEMENTS}

The author held Walter C. Sumner and Weston Fellowships. This work also received financial support from the GRAND Network of Centres of Excellence, the Natural Sciences and Engineering Research Council of Canada, and Google Research.

\section{REFERENCES}

Ballance, O. J. (2013). MALL-Somewhere between the tower, the field, the classroom, and the market: A reply to Professor Stockwell's response. Language Learning \& Technology (LLT), 17(1), 37-46.

Burston, J. (2014). The Reality of MALL: Still on the Fringes. CALICO Journal, 31(1), 103-125. doi:10.11139/cj.31.1.

Carey, S. (2004). Bootstrapping and the origin of concepts. Daedalus (Winter), 59-68.

Demmans Epp, C. (2013). Mobile adaptive communication support for vocabulary acquisition. In H. C. Lane, K. Yacef, J. Mostow, \& P. Pavlik (Eds.), Artificial intelligence in education (AIED) (pp. 876879). Memphis, TN: Springer. doi:10.1007/978-3-642-39112-5_135

Gambino, C. P., Acosta, Y. D., \& Grieco, E. M. (2014). English-speaking ability of the foreign-born population in the United States: 2012 (No. ACS-26). US Census Bureau. Retrieved from http://www.census.gov/library/publications/2014/acs/acs-26.html

Godwin-Jones, R. (2010). Emerging technologies from memory palaces to spacing algorithms: Approaches to second-language vocabulary learning. Language Learning \& Technology (LLT), 14(2), 4-11.

Graves, M. F. (2013). Teaching vocabulary to English language learners. New York: Teachers College Press.

$\mathrm{Ma}, \mathrm{Q}$. (2013). Computer assisted vocabulary learning: Framework and tracking users' data. LearnerComputer Interaction in Language Education: A Festschrift in Honor of Robert Fischer. CALICO Journal, 230-243. doi:10.11139/cj.0.0.230-243

Saiz, A., \& Zoido, E. (2005). Listening to what the world says: Bilingualism and earnings in the United States. Review of Economics and Statistics, 87(3), 523-538. doi:10.1162/0034653054638256

Swain, M. (1995). Three functions of output in second language learning. In G. Cook \& B. Seidlhofer (Eds.), Principles and practice in applied linguistics. Oxford: Oxford University Press. Retrieved from http://www.scribd.com/doc/105840639/Swain-1995-Three-functions-of-output-insecond-language-learning

Wagner, R. K., Muse, A. E., \& Tannenbaum, K. R. (Eds.). (2007). Vocabulary acquisition: Implications for reading comprehension. New York: Guilford Press. 